\title{
Pengolahan Limbah Minyak Pelumas dengan Menggunakan Metode Elektrokoagulasi
}

\author{
Lailan Ni'mah",", Fauzah Fyanidah ${ }^{1}$, M. Danan Maulana ${ }^{1}$ \\ ${ }^{1}$ Program Studi Teknik Kimia, Fakultas Teknik, Universitas Lambung Mangkurat \\ J1. Jend. A. Yani KM. 35,5 Banjarbaru, Kalimantan Selatan 70714 \\ *email: 1ailan.nimah@gmail.com
}

\begin{abstract}
Motor vehicles and the use of factory machinery is the largest user of lubricant oil. The waste generated by motor vehicles and plant machinery is included into B3 waste which needs special handling. There are many methods that can be used to handle lubricant wastes, such as electroplates, adsorption, acid clay treatments and electrocoagulation. In this study used electrocoagulation because this method is easy and not too dangerous because there is no addition of chemicals. The objective of this study was to study electrocoagulation method using aluminum and stainless steel electrodes and the effect of time to decrease of Fe metal content. This electrocoagulation treats lubricating oil waste electrically so that the ions present in the waste are absorbed by the binding coagulant that is released electrode so that there will be bonds between metal ions with coagulant. This research was conducted first reactor filled with lubricant oil waste containing Fe up to $1000 \mathrm{~mL}$. The anode (aluminum) is connected to the positive pole, whereas the cathode (stainless steel) is connected to the negative pole of the current rectifier (adapter). The electric current passing through the anode and cathode causes the displacement of the electrons from the cathode to the anode. Voltage variations used are 12 volts, 18 volts and 24 volts and 5A strong current with long stirring of each variation for 2 hours, 2.5 hours and 3 hours and plate plate variations used are $100 \mathrm{~mm} \times 25 \mathrm{~mm} \times 0.5 \mathrm{~mm}, 100 \mathrm{~mm} \times 50 \mathrm{~mm} \times 0.5 \mathrm{~mm}$ and $100 \mathrm{~mm} \times 75 \mathrm{~mm} \times 0.5 \mathrm{~mm}$. The most effective results in the study using electrocoagulation with 24 volt voltage with time of 3 hours for plate $100 \mathrm{~mm} \times 75 \mathrm{~mm} \times 0.5 \mathrm{~mm}$ Fe content of remaining metal $26.47 \mathrm{ppm}$.
\end{abstract}

Keywords: Used lubricating oil, electrocoagulation, aluminium, stainless steel, Fe

\section{Pendahuluan}

Penggunaan minyak pelumas yang semakin meningkat tiap tahunnya, maka limbah yang dihasilkan juga akan semakin meningkat. Limbah dari minyak pelumas termasuk kedalam limbah B3 yang perlu mendapatkan penanganan khusus. Limbah dari minyak pelumas biasanya banyak mengandung Fe. Dengan terdapatnya logam berat $\mathrm{Fe}$ pada limbah minyak pelumas dikhawatirkan akan mengganggu lingkungan dan kesehatan manusia. Oleh karena itu diperlukan suatu penelitian mengenai penurunan kandungan logam Fe dari limbah minyak pelumas.

Salah satu metode yang bisa digunakan dalam upaya menurunkan kadar Fe yang terkandung di dalam limbah minyak pelumas adalah secara elektrokoagulasi dengan elektroda alumunium sebagai katoda dan stainless steel sebagai anoda. Metode elektrokoagulasi memiliki keuntungan dibandingkan dengan koagulasi yakni elektrokoagulasi tidak menggunakan bahan kimia sedangkan koagulasi menggunakan bahan kimia [1].

Penelitian ini bertujuan untuk mengetahui proses elektrokoagulasi dalam penurunan kandungan logam $\mathrm{Fe}$ dalam limbah minyak pelumas menggunakan elektroda alumunium sebagai katoda dan stainless steel sebagai anoda serta untuk mengetahui pengaruh tegangan, ukuran plat dan waktu pada metode elektrokoagulasi yang paling berpengaruh terhadap penurunan kandungan logam Fe dalam limbah minyak pelumas.

\section{Minyak Pelumas (Oli) Bekas}

Minyak pelumas adalah suatu produk minyak bumi yang termasuk fraksi distilat berat dan mempunyai trayek titik didih $300{ }^{\circ} \mathrm{C}$. Minyak pelumas merupakan salah satu produk minyak bumi. Fungsi minyak pelumas meliputi: mengurangi gesekan dan keausan, mendinginkan komponen mesin, membantu merapatkan kompresi serta membersihkan komponen mesin. Minyak pelumas yang digunakan untuk melumasi mesin mempunyai persyaratan antara lain: tahan suhu tinggi, tahan karat dan korosi, mampu mencegah terjadinya busa serta mampu mengalir pada suhu rendah. Pemilihan kekentalan minyak pelumas yang kurang tepat dapat menghambat kerja mesin. Minyak pelumas yang terlalu encer tidak akan berfungsi dengan baik dan bila terlalu kental akan menghambet kerja mesin karena tahanan yang tinggi [2]. 
Berdasarkan kriteria limbah yang dikeluarkan oleh Kementrian Lingkungan Hidup, oli bekas termasuk kategori limbah B3. Meski oli bekas masih bisa dimanfaatkan, bila tidak dikelola dengan baik, ia bisa membahayakan lingkungan. Sejalan dengan perkembangan kota dan daerah, volume oli bekas terus meningkat seiring dengan pertambahan jumlah kendaraan bermotor dan mesin-mesin bermotor. Di daerah pedesaan sekalipun, sudah bisa ditemukan bengkel-bengkel kecil, yang salah satu limbahnya adalah oli bekas. Dengan kata lain, penyebaran oli bekas sudah sangat luas dari kota besar sampai ke wilayah pedesaan diseluruh Indonesia [3].

Berdasarkan Pasal 1 Ayat 2 Peraturan Pemerintah No. 18/1999, limbah B3 adalah sisa suatu usaha dan/atau kegiatan yang mengandung bahan berbahaya dan/atau beracun yang karena sifat dan/atau konsentrasinya dan/atau jumlahnya, baik secara langsung maupun tidak langsung dapat mencemarkan dan/atau merusak lingkungan hidup, dan/atau dapat membahayakan lingkungan hidup, kesehatan, kelangsungan hidup manusia serta makhluk hidup lain [4]. Standar baku mutu limbah cair menurut keputusan Menteri Negara Lingkungan Hidup nomor KEP-51/MENLH/10/1995 dapat dilihat pada Tabel 1.

Tabel 1. Standar baku mutu limbah cair menurut keputusan Menteri Negara Lingkungan Hidup nomor KEP51/MENLH/10/1995

\begin{tabular}{cccc}
\hline No. & PARAMETER & SATUAN & MUTU LIMBAH CAIR \\
\hline 1. & $\mathrm{pH}$ & & $6,0-9,0$ \\
2. & Besi Terlarut $(\mathrm{Fe})$ & $\mathrm{mg} / \mathrm{L}$ & $5-10$ \\
3. & Timbal $(\mathrm{Pb})$ & $\mathrm{mg} / \mathrm{L}$ & $0,1-1$ \\
\hline
\end{tabular}

\section{Prinsip Elektrokoagulasi}

Prinsip kerja elektrokoagulasi didasari oleh konsep fisika dasar, yaitu pengaruh gaya magnet terhadap ionion yang terdapat pada medan magnet yang kemudian ditangkap oleh plat. Selain itu suatu aliran listrik mampu menyebabkan destabilisasi unsur-unsur partikel atau senyawa terikat, diantaranya senyawa logam, hidrokarbon dan organik. Saat tidak stabil, muatan partikel dan ion akan menarik unsur partikel atau senyawa lain sampai terbentuk senyawa yang sangat stabil [5]. Proses elektrokoagulasi [4], dapat digambarkan pada Gambar 1:

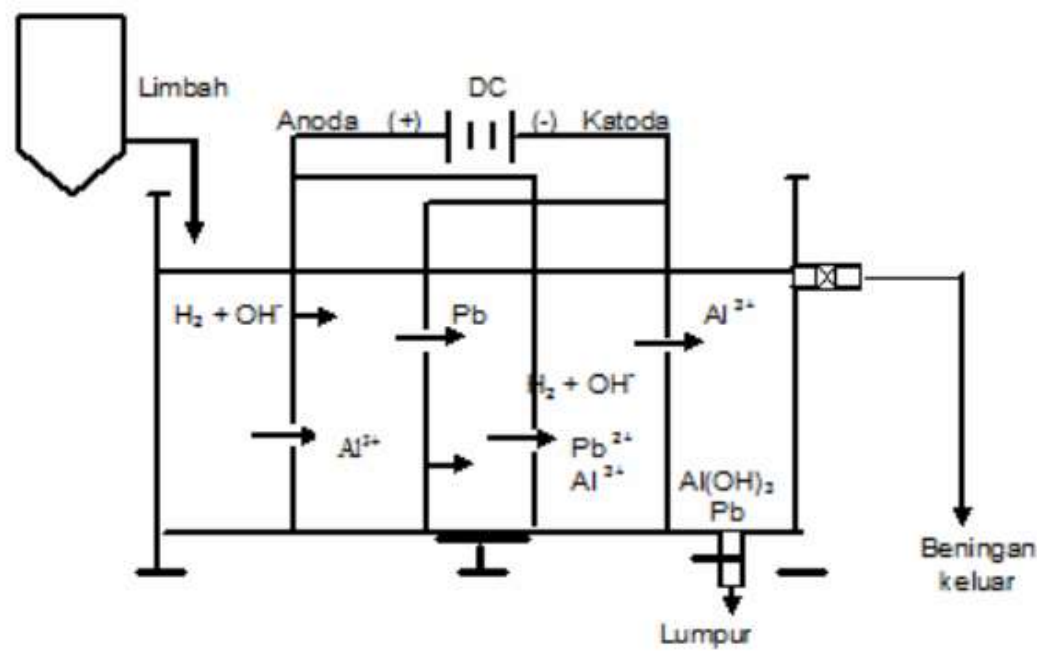

Gambar 1. Proses Elektrokoagulasi

Proses elektrokoagulasi memiliki kelebihan antara lain [6]:

1. Elektrokoagulasi memerlukan peralatan sederhana dan mudah untuk dioperasikan.

2. Flok yang dihasilkan elektrokoagulasi ini sama dengan flok yang dihasilkan koagulasi biasa.

3. Lebih cepat mereduksi kandungan koloid/partikel yang paling kecil, hal ini disebabkan pengaplikasian listrik ke dalam air sehingga akan mempercepat pergerakan mereka didalam air, dengan demikian akan memudahkan proses.

4. Dapat memberikan efisiensi proses yang cukup tinggi untuk berbagai kondisi, dikarenakan tidak dipengaruhi temperatur.

5. Tidak diperlukan pengaturan $\mathrm{pH}$. 
6. Tanpa menggunakan bahan kimia tambahan.

Elektroda yang digunakan pada umumnya adalah alumunium karena memiliki sifat sebagai koagulan. Kation menghidrolisis di dalam air membentuk sebuah hidroksi dengan spesies dominan. Untuk kasus anoda alumunium maka reaksi yang terjadi adalah:

$$
\begin{array}{ll}
\mathrm{Al}+\mathrm{H}_{2} \mathrm{O} & \rightarrow \mathrm{AlOH}^{2+}+\mathrm{H}^{+} \\
\mathrm{AlOH}^{2+}+\mathrm{H}_{2} \mathrm{O} & \rightarrow \mathrm{Al}(\mathrm{OH})_{2}^{+}+\mathrm{H}^{+} \\
\mathrm{Al}(\mathrm{OH})^{2+}+\mathrm{H}_{2} \mathrm{O} & \rightarrow \mathrm{Al}(\mathrm{OH})_{3}{ }^{0}+\mathrm{H}^{+}
\end{array}
$$

Kation bermuatan tinggi mendestabilisasi beberapa partikel koloid dengan membentuk polivalen polihidroksi kompleks. Senyawa kompleks ini mempunyai sisi yang mudah diadsorbsi, membentuk gumpalan (aggregates) dengan polutan. Pelepasan gas hidrogen akan membantu pencampuran dan pembentukan flok. Flok yang dihasilkan oleh gas hidrogen akan diflotasikan kepermukaan reaktor [7].

\section{Metodologi}

Penelitian ini menggunakan metode elektrokoagulasi dengan elektroda alumunium. Limbah minyak pelumas didapat dari bengkel disekitar kota Banjarbaru, Kalimantan Selatan. Penelitian ini dilaksanakan di Laboratorium Operasi Teknik Kimia, Program Studi Teknik Kimia, Universitas Lambung Mangkurat. Penentuan konsentrasi Fe dengan analisis kuantitatif menggunakan UV-Vis Spektofotometri dilakukan di Balai Lingkungan Hidup (BLH), Martapura.

\section{Alat Utama}

Alat utama yang digunakan pada penelitian ini adalah:

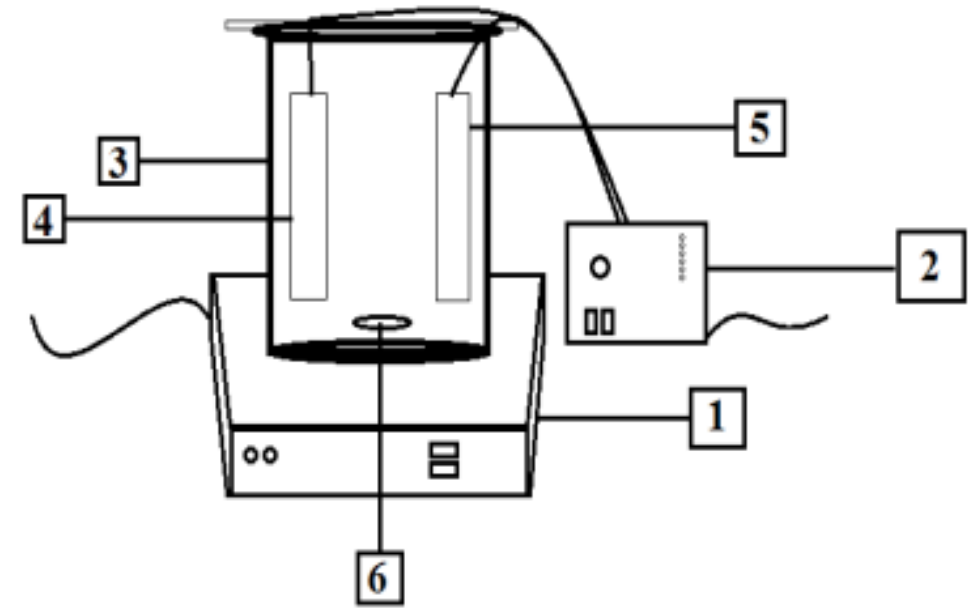

Keterangan:

1. Hot Plate and Stirrer

2. Adaptor

3. Reaktor

4. Elektroda Alumunium

5. Elektroda Stainless Steel

6. Magnetic

Gambar 2. Rangkaian Alat Metode Elektrokoagulasi

\section{Alat Pendukung}

Alat pendukung yang digunakan pada penelitian ini adalah botol semprot, penggaris, amplas, selotip, corong dan botol sampel.

\section{Bahan}

Bahan utama yang digunakan dalam penalitian ini adalah limbah minyak pelumas yang mengandung $\mathrm{Fe}$ diperoleh dari bengkel yang berada di kota Banjarbaru, Kalimantan Selatan, serta elektroda alumunium dan stainless steel dengan ukuran $100 \mathrm{~mm} \times 25 \mathrm{~mm} \times 0,5 \mathrm{~mm} ; 100 \mathrm{~mm} \times 50 \mathrm{~mm} \times 0,5 \mathrm{~mm}$ dan $100 \mathrm{~mm} \times 75 \mathrm{~mm} \times 0,5 \mathrm{~mm}$.

\section{Prosedur Penelitian}

1. Persiapan Bahan Baku: Limbah yang mengandng Fe terlebih dahulu dianalisis kadar awal sampelnya di BLH (Balai Lingkungan Hidup), kemudian memotong lempengan alumunium dan stainless steel dengan ukuran $100 \mathrm{~mm} \times 25 \mathrm{~mm} \times 0,5 \mathrm{~mm} ; 100 \mathrm{~mm} \times 50 \mathrm{~mm} \times 0,5 \mathrm{~mm}$ dan $100 \mathrm{~mm} \times 75 \mathrm{~mm} \times 0,5 \mathrm{~mm}$.

2. Persiapan Alat: Rangkai alat seperti pada gambar 2 lalu kalibrasi alat sebelum dipakai. 
3. Proses Elektrokoagulasi: Pertama-tama reaktor diisi dengan limbah minyak pelumas yang mengandung Fe sampai dengan $1000 \mathrm{~mL}$. Anoda (alumunium) dihubungkan dengan kutub positif, sedangkan katoda (stainless steel) dihubungkan dengan kutub negatif pada penyearah arus (adaptor). Variasi yang digunakan adalah tegangan yaitu 12 volt, 18 volt dan 24 volt; besar masing-masing plat yaitu $100 \mathrm{~mm} \times 25 \mathrm{~mm} \times 0,5 \mathrm{~mm}$; $100 \mathrm{~mm} \times 50 \mathrm{~mm} \times 0.5 \mathrm{~mm}$ dan $100 \mathrm{~mm} \times 75 \mathrm{~mm} \times 0.5 \mathrm{~mm}$ dan waktu yaitu 2 jam; 2,5 jam dan 3 jam. Cairan limbah yang sudah melalui proses elektrokoagulasi dimasukkan di dalam botol sampel dan dianalisis lagi dengan menggunakan metode UV-Vis Spektofotometri untuk mengukur penurunan kadar Fe.

\section{Hasil dan Pembahasan}

Elektrokoagulasi merupakan upaya mengurangi atau menurunkan senyawa logam yang terdapat dalam limbah cair dengan menggunakan plat yang dialirkan aliran listrik searah (DC) agar logam yang tidak diinginkan menggumpal dan menempel pada kutub negatif. Dipilih alumunium dan stainless steel sebagai elektroda. Kandungan logam Fe pada pelumas sebelum pengujian adalah 29,5 ppm. Berikut adalah Gambar 3 untuk hasil percobaan pada tegangan 12 volt, Gambar 4 untuk percobaan pada tegangan 18 volt dan Gambar 5 untuk percobaan pada 24 volt:

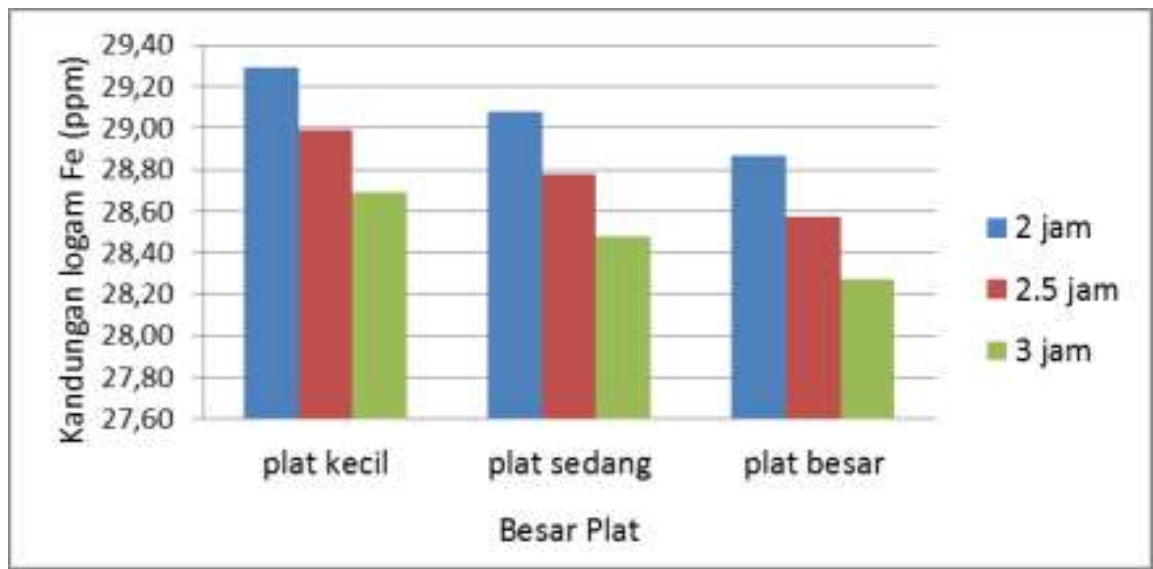

Gambar 3. Perbandingan antara ukuran plat, waktu terhadap kandungan logam Fe total (ppm) pada 12 volt

Berdasarkan Gambar 3 pada tegangan 12 volt dapat dilihat bahwa terjadi penurunan kandungan logam Fe pada limbah pelumas, hal ini menunjukkan bahwa semakin lama waktu proses elektrokoagulasi maka akan semakin banyak kandungan logam $\mathrm{Fe}$ yang terikat [1]. Kandungan logam $\mathrm{Fe}$ awal sebelum dilakukan elektrokoagulasi adalah 29,5 ppm, setelah dilakukan proses elektrokoagulasi kandungan logam Fe tersebut semakin turun dimana penurunan terbesar terjadi pada waktu 3 jam dengan kandungan logam Fe sebesar 28,22. Pada gambar 3 diatas dapat dilihat bahwa ukuran plat yang digunakan juga berpengaruh, dimana penurunan kandungan logam $\mathrm{Fe}$ yang terbesar terjadi pada plat dengan ukuran $100 \mathrm{~mm} \times 75 \mathrm{~mm} \times 0,5 \mathrm{~mm}$.

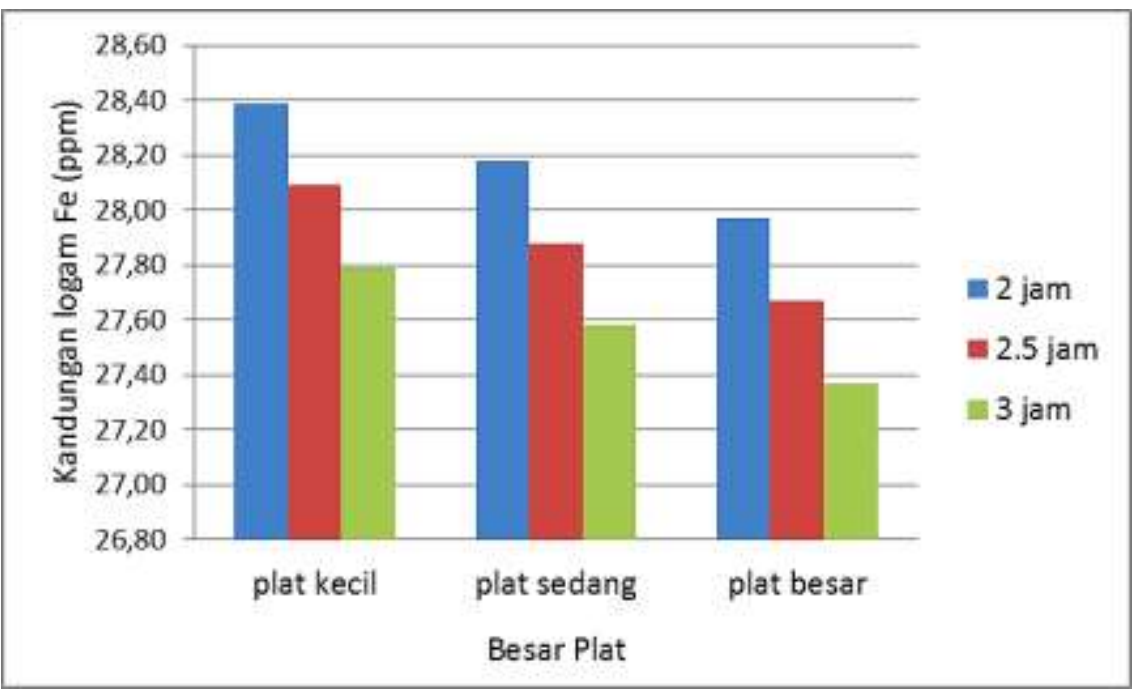

Gambar 4. Perbandingan antara ukuran plat, waktu terhadap kandungan logam Fe total (ppm) pada 18 volt 
Hasil pada Gambar 4 untuk tegangan 18 volt juga menunjukkan adanya penurunan kandungan logam Fe. Penurunan tersebut dipengaruhi oleh ukuran plat dan lamanya waktu elektrokoagulasi. Dimana penurunan terbesar terjadi pada ukuran plat $100 \mathrm{~mm} \times 75 \mathrm{~mm} \times 0,5 \mathrm{~mm}$ dengan waktu elektrokoagulasi selama 3 jam. Kandungan logam Fe awal sebesar 29,5 ppm turun menjadi 27,31 ppm.

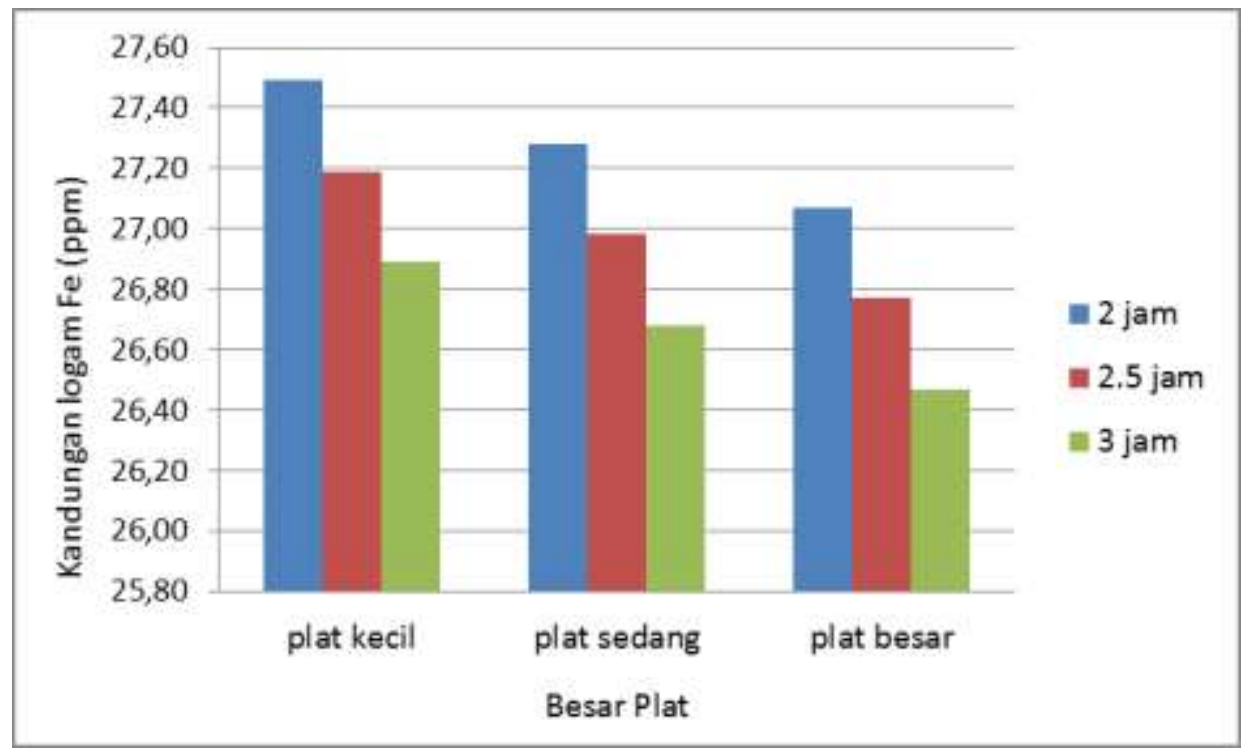

Gambar 5. Perbandingan antara ukuran plat, waktu terhadap kandungan logam Fe total (ppm) pada 24 volt

Begitu pula hasil pada gambar 5 untuk tegangan 24 volt juga menunjukkan adanya penurunan kandungan logam Fe. Penurunan tersebut dipengaruhi oleh ukuran plat dan lamanya waktu elektrokoagulasi. Dimana penurunan terbesar terjadi pada ukuran plat $100 \mathrm{~mm} \times 75 \mathrm{~mm} \times 0,5 \mathrm{~mm}$ dengan waktu elektrokoagulasi selama 3 jam. Kandungan logam Fe awal sebesar 29,5 ppm turun menjadi 26,44 ppm.

Berdasarkan gambar 3, gambar 4 dan gambar 5 dapat disimpulkan bahwa semakin lama waktu, semakin besar ukuran plat dan semakin besar tegangan yang digunakan penurunan kandungan logam pun semakin besar, dimana kandugan logam Fe yang semula sebesar 29.5 ppm turun menjadi $29.2 \mathrm{ppm}$ s/d $26.47 \mathrm{ppm}$. Dari tiga variasi waktu, ukuran plat dan tegangan, penurunan kandungan logam Fe total terbesar terjadi pada waktu 3 jam, tegangan 24 volt dan ukuran plat $100 \mathrm{~mm} \times 75 \mathrm{~cm} \times 0.5 \mathrm{~mm}$ yaitu sebesar $26.47 \mathrm{ppm}$ atau sebesar $10.27 \%$. Hal ini dikarenakan semakin lama waktu maka semakin lama pula waktu kontak antara pelumas dengan plat, dimana kuatnya tegangan yang dialirkan pada plat akan mengikat logam Fe pada kutub negatif. Ukuran plat yang besar juga menyebabkan logam yang terikat semakin besar hal ini dikarenakan daya elektrostatiknya dalam mereduksi dan mengoksidasi ion logam dalam larutan akan semakin besar. Reaksi yang terjadi pada proses elektrokoagilasi adalah sebegai berikut:

1. Pada anoda

$$
\mathrm{Fe} \rightarrow \mathrm{Fe}^{2+}+2 \mathrm{e}
$$

2. Pada katoda

$$
\mathrm{Al}^{2+}+3 \mathrm{e} \rightarrow \mathrm{Al}
$$

3. Di sekitar elektroda

$$
\mathrm{Fe}^{2+}+2(\mathrm{OH})^{+} \rightarrow \mathrm{Fe}(\mathrm{OH})_{2}
$$

\section{Kesimpulan}

Berdasarkan penelitian yang telah dilakukan dapat diambil kesimpulan sebagai berikut:

1. Penurunan kandungan logam Fe dalam limbah minyak pelumas yang paling besar setelah proses elektrokoagulasi $26,47 \mathrm{ppm}$ pada 24 volt, 3 jam dan ukuran plat $100 \mathrm{~mm} \times 75 \mathrm{~mm} \times 0,5 \mathrm{~mm}$.

2. Semakin lama waktu, semakin besar ukuran plat dan semakin besar tekanan yang digunakan maka semakin besar penurunan kandungan logam Fe dalam limbah minyak pelumas. 
Chemica

Volume 4, Nomor 1, Juni 2017, 21-26

ISSN: $2355-8776$

\section{Daftar Pustaka}

[1]. Bambang, P. dan Mining Harsanti. 2010. Pengolahan Limbah Cair Tekstil Menggunakan Proses Elektrokoagulasi dengan Sel Al. Universitas Jendral Achmad Yani. Bandung.

[2]. Siswanti. 2010. Pengaruh Penambahan Aditif Proses Daur Ulang Minyak Pelumas Bekas terhadap SifatSifat Fisis. Universitas Pembangunan Nasional "Veteran". Yogyakarta.

[3]. Winoto, Pandu, dkk. 2014. Daur Ulang Oli Bekas Menjadi Minyak dengan Distilasi. Jakarta.

[4]. Pratiwi, Yuzana. 2013. Pengolahan Minyak Pelumas Bekas Menggunakan Metode Acid Clay Treatment. Universitas Tanjungpura. Pontianak.

[5]. Saranto. 2000. Penurunan Kadar Chrom Limbah Cair Industri Penyamakan Kulit dengan Elektroflokulasi. Sekolah Tinggi Teknologi Lingkungan. Yogyakarta.

[6]. Johanes, H. 1978. Listrik dan Magnet. Balai Pustaka. Jakarta.

[7]. Huheey, J.E. 1978. Inorganic Chemistry: Principles of Structure and Reactivity. Second Edition. Harper \& Row Publishers, Inc. New York. 